\title{
Tras la estela de Corte-Real. \\ El poema Sepúlveda e Lianor en la memoria de Lope de Vega, Cervantes, Calderón, Solórzano Pereira y Tirso de Molina
}

\author{
Hélio J. S. Alves \\ Universidade de Évora \\ halves@uevora.pt
}

Recepción: 15/10/2013, Aceptación: 09/11/2013, Publicación: 20/12/2013

\section{Resumen}

A pesar de olvidado y hasta vilipendiado por la crítica e historiografía literarias desde el siglo xIx, Jerónimo Corte-Real (¿?-Évora, 1588) fue un poeta portugués de gran importancia e influencia en el Siglo de Oro español. Autor de extensos poemas sobre la expansión portuguesa en Oriente y la batalla de Lepanto, que tuvieron una repercusión significativa en España, Corte-Real compuso también otro poema sobre un asunto mucho más casero, la historia del infeliz matrimonio formado por Lianor y Manuel Sepúlveda, que solo se publicaría en 1594, en Lisboa, algunos años después de la muerte del poeta. Este artículo argumenta que, aunque nunca contó con una traducción en español, el poema Sepúlveda e Lianor fue leído al más alto nivel, como se ve en obras de Solórzano Pereira y Tirso de Molina, llegando a incorporarse en la memoria alusiva de Cervantes, Lope de Vega y Calderón. La intertextualidad con el Sepúlveda e Lianor, aparentemente mediada por textos lusitanos sobre el canon poético del país vecino (se estudia el caso de Pedro de Mariz), evidencia la necesidad de modificar sustancialmente la interpretación que se concede a algunos textos de estos autores mayores de la literatura espańola.

Palabras clave

Jerónimo Corte-Real; Pedro de Mariz, Lope de Vega; Miguel de Cervantes; Pedro Calderón de la Barca; Juan de Solórzano Pereira; Tirso de Molina

\footnotetext{
Abstract

On the trail of Corte-Real: The poem Sepúlveda e Lianor in the memory of Lope de Vega, Cervantes, Calderón, Solórzano Pereira and Tirso de Molina

Although forgotten and even maligned by literary criticism and history since the 19th
} 
century, Jerónimo Corte-Real (?-1588) was a Portuguese poet of great importance and influence in the Spanish Golden Age. The author of large poems about Portuguese expansion in the East and the battle of Lepanto which had a significant impact in Spain, Corte-Real also composed another poem about a much more domestic affair, the story of the unfortunate marriage between Lianor and Manuel Sepúlveda, that would be published only in 1594, in Lisbon, a few years after the poet's death. This article argues that, although never translated into Spanish, the poem Sepúlveda e Lianor was read at the highest level, as witnessed by the works of Solórzano Pereira and Tirso de Molina, and even became part of the poetic memory of Cervantes, Lope de Vega and Calderón. Intertextuality with Sepúlveda e Lianor, apparently mediated by Portuguese texts about the poetic canon of the neighbouring country (the case of Pedro de Mariz is studied here), shows the need to change substantially the interpretation given to some texts written by these major authors of Spanish literature.

\section{Keywords}

Jerónimo Corte-Real; Pedro de Mariz; Lope de Vega; Miguel de Cervantes; Pedro Calderón de la Barca; Juan de Solórzano Pereira; Tirso de Molina

Un poema, para serlo en plenitud, tiene que tener lectores. Si es grande, tiene que tener lectores grandes también. Fue este el caso, como veremos, de Sepúlveda e Lianor. Antes de haber sido dado a la estampa, la fama de su autor ya corría por Portugal y España, a pesar del desconocimiento del último fruto de su pluma. Con anterioridad a 1594, Jerónimo Corte-Real (¿?/1588) era, no solo un poeta con dos obras impresas (Sucesso do Segundo Cerco de Diu, en 1574 y Felicissima Victoria de Lepanto, en 1578), sino también un escritor reconocido por la calidad de sus composiciones. Aun así, la divulgación póstuma del texto sobre la desafortunada pareja parece haber causado una honda impresión, introduciendo una dimensión nueva en la opinión general acerca del poeta, a juzgar por los testimonios que presentamos a continuación.

\section{Pedro de Mariz, Diálogos de Vária História}

El documento fundador de la recepción del poema, y aquel que manifiesta mejor el paso de un aprecio considerable por el autor a una admiración que solo se concede a las mayores obras de arte, es Diálogos de Vária História, de Pedro de Mariz. Con una primera edición salida de la imprenta en el mismo año que el Sepúlveda y otra entre tres y cinco años después, los Diálogos constituyen, entre la edición 
original y su revisión y ampliación, un testigo significativo de los cambios que se están sucediendo en la década de los '90 del siglo Xvi en lo que se refiere al canon poético portugués ${ }^{1}$. Respecto a Corte-Real, el texto de Mariz y sus modificaciones no solo revelan una alteración en el ámbito de la consciencia de los valores poéticos, y especialmente épicos-narrativos, por aquel entonces en Portugal, sino que indican también el momento institucional de los moldes de la recepción del Sepúlveda entre los escritores ibéricos más importantes de los años y décadas inmediatamente posteriores.

En la primera edición, Mariz — como señaló el bibliógrafo Barbosa Machado - atribuye, escribiéndolo en latín en el margen, el término elegantísimo para referirse a la forma que Corte-Real le había dado al relato de la victoria de D. João de Castro sobre el sultán de Cambay (está implícito que es en el poema del Sucesso do Segundo Cerco de Diu). ${ }^{2}$ Exactamente el mismo epíteto, pero esta vez en portugués y en el cuerpo del texto, se le concede a un poeta nombrado tan solo por perífrasis y antonomasia. Refiriéndose al célebre viaje inaugural de Vasco da Gama, Mariz escribe que sus «inumeráveis perigos [...] pelo nosso Homero Lusitano em elegantíssimo Poema estão bastantemente encomendados à imortalidade». ${ }^{3}$ Obviamente, está haciendo alusión a Camóes. Y si tanto él como Corte-Real comparten el adjetivo elegantísimo, está aquí patente que el autor de Os Lusiadas descuella y se encuentra, en solitario, en la cumbre del Parnaso lusitano.

En la edición de 1597-99, sin embargo, cuando el poema de Sepúlveda e Lianor era ya conocido por el público, Mariz procede a curiosas alteraciones y añadidos. Mantiene en el margen la nota sobre Corte-Real, pero reescribe el pasaje sobre el viaje de Gama de tal forma que la mención a Camóes desaparece por completo. Al mismo tiempo, aumenta el número de alusiones a uno y otro poeta. El autor de Os Lusíadas surge referido como «Luís de Camóes em os seus famosos Lusíadas»" "o nosso Camões» y «o verdadeiro Poeta Luís de Camóes». ${ }^{4}$ A su vez, Corte-Real sirve ahora de autoridad a propósito de las acciones del gobernador Nuno da Cunha en la India y la batalla naval de Lepanto. ${ }^{5}$ En ninguno de estos casos asoma a su texto ni una sola palabra de alabanza al poeta más allá de aquel «elegantísimo» que ya conocíamos de la edición de 1594. Sin embargo, Mariz introduce una profunda innovación al relatar brevemente el célebre naufragio, cuando apunta que Manuel de Sousa Sepúlveda,

...salvando toda a gente e algũa fazenda da fúria do mar, o não pôde fazer das mãos dos bárbaros Cafres, que com treiçôes e enganos o roubaram, e lhe mataram muitos de sua companhia, e a ele e sua mulher e filhos constrangeram a passar a mais lastimo-

1. La primera edición: Mariz (1594); la segunda: Mariz (1597-1599).

2. Mariz, en la edición de 1594 , fol. 213v.

3. Ibidem, fol. $185 \mathrm{v}$.
4. Siempre en el Diálogo IV, en los folios $219 \mathrm{r}$, $139 \mathrm{v}$ y $213 \mathrm{v}$, respectivamente.

5. En el Diálogo V, cap. 1 (fol. 317r) y en el Diálogo II, cap. 5 (fol. s/n). 
sa morte que a miséria humana experimentou, como o verdadeiro Poeta Hieronymo Corte Real chora e canta no seu heróico Poema que ele dizia lhe saíra d'alma. ${ }^{6}$

Camóes ya no asoma como el "Homero Lusitano" y se adopta un curioso paralelismo: tanto él como Corte-Real pasan a merecer el título, laudatorio si bien que ambiguo, de "o verdadeiro Poeta». La paridad que el calificativo elegantísimo trajo a ambos, destruida por la evidente exaltación de Os Lusíadas en la designación escogida en 1594, fue retomada en un plano superior en 1597-99, por una verdadera equivalencia de valores entre los dos poemas. Accidentalmente o no, ahora ninguno se sobrepone al otro. Incluso pensando en la posibilidad de que la alteración haya sido menos intencionada y significativa de lo que nos parece, la verdad es que ésta forjó la idea de valorización paralela de los dos poetas portugueses que encontraremos en documentos posteriores.

\section{Lope de Vega, de la Arcadia a las Essequie}

En una de sus más celebradas novelas, la Arcadia, que es además su primer gran éxito editorial, Félix Lope de Vega Carpio ya sitúa a los dos poetas lusitanos en encomio paralelo. En una "Exposición de los nombres Históricos, y Poéticos" incluida en la obra desde la primera edición de 1598, Lope de Vega evidencia la paridad de los épicos portugueses en una frase en la que alude al río Tajo: «donde entra en el mar por la insigne Lisboa, el rarísimo Camoes y el estudioso Corte-Real le han dado inmortal nombre» ${ }^{7}$. En la novela propiamente dicha, tanto uno como otro poeta ya habían sido mencionados, esta vez en una lista vasta y aparentemente desordenada de autores ibéricos coevos. ${ }^{8}$ Ahí, en medio de una serie de nombres, aparece referido Corte-Real, con el "excelente» Camóes y el «toledano» Gregorio Hernández por un lado, y «don Francisco de Borja, comendador mayor de Montesa», por otro. ${ }^{9}$ No podemos saber si las menciones en la Arcadia tendrían ya en cuenta al Sepúlveda elogiado por Pedro de Mariz, pero la verdad es que este poema había contribuido decisivamente, como se verá, para que Lope de Vega hubiera puesto a Corte-Real en su canon de autores modernos.

6. Diálogo V, fol. 334v. La expresión «que lhe saíra d'alma» la repetirá o plagiará Santa Maria (1744, II: 241).

7. En los ejemplares que he consultado de las ediciones de 1598 y 1599 de la Arcadia en la Biblioteca Nacional de Espańa, no constaba la "Exposición", y así lo he señalado en trabajos que he publicado anteriormente. La edición reciente de Sánchez Jiménez (2012), sin embargo, se sirve de ejemplares de la princeps, pertenecientes a otras bibliotecas que, aparen- temente, incluyen el mismo apéndice.

8. Lope de Vega, Arcadia, prosas y versos, ed. 1598, Libro V, fol. 292 (ed. 2012, p. 639).

9. Este D. Francisco de Borja era alguien próximo a Lope por aquel entonces, y por eso escribió el prefacio de su primer poema épico, La Dragontea, impreso en el mismo año de la edición princeps de la Arcadia. A Gregorio Hernández de Velasco, natural de Toledo, se le conocía como el traductor al español del Parto de la Virgen de Sannazaro e de la Eneida de Virgilio, poemas épicos. 
El testimonio más elocuente que existe del aprecio de Lope de Vega por poetas lusitanos se encuentra en el Laurel de Apolo de 1630, un conjunto de silvas donde se elogian a escritores de toda la Península. No se ha caído en la cuenta de que en la Silva Tercera, a manera de introducción, antes incluso de empezar el rol de personalidades ilustres, Lope identifica a las gentes portuguesas sobre todo a través de dos acontecimientos y de dos poemas que los relatan:

Su gente belicosa

Pasó la Trapobana

Con impulso divino y fuerza humana,

Sujetando su mano poderosa

20 Los etíopes rudos y abrasados,

Y viendo los remotos horizontes

De los cafres pintados,

Bárbaros lotófagos arrogantes,

Mares desnudos y vestidos montes,

25 Teatro infausto de los dos amantes,

Bellísima Leonor, Manuel de Sosa,

Que hoy llora su tragedia lastimosa

El mar, arrepentido

De haberlos a su playa conducido,

30 Cuando, abrazada con dos niños bellos,

Bebió sus almas, y ellos

La suya al mismo tiempo, cuyas vidas

De lágrimas, de fe, de amor nacidas,

Pagó su esposo con perder el seso,

35 Que no se debe más a un mal suceso. ${ }^{10}$

Los primeros versos citan la proposición de Os Lusíadas, especialmente en la primera octava, donde dice:

Passaram ainda além da Taprobana,

Em perigos e guerras esforçados

Mais do que prometia a força humana.

«Taprobana», con metátesis de la $r, \mathrm{y}$ «força humana» son el nombre propio y la clausula que identifican textualmente, por alusión, a la epopeya de Camóes. Estamos ante el mejor homenaje que se le puede prestar a un poema: citar y glosar el célebre tema, con la convicción de que los lectores sabrán ver éste reconocimiento.

Rápidamente, sin embargo, el paso se desplaza desde Oriente hasta África (a partir de "los etíopes») y permanece en este continente durante el resto del

10. Lope de Vega, Laurel de Apolo, Silva III, vv. 16-35. 
párrafo. De los veinte versos, solo tres o cuatro no hablan de África como palco del caso trágico de Sepúlveda. El episodio lo relata el gigante Adamastor en $O s$ Lusiadas, y Lope de Vega muestra que lo conoce de ahí, visto que la silva espańola manifiesta contacto intertextual con los versos de Camóes:

Verão morrer com fome os filhos caros,

Em tanto amor gerados e nacidos;

Verão os cafres, ásperos e avaros,

Tirar à linda dama seus vestidos;

Os cristalinos membros e preclaros

À calma, ao frio, ao ar verão despidos

(...)

E verão mais os olhos que escaparem

De tanto mal, de tanta desventura,

Os dous amantes míseros ficarem

(...)

Com lágrimas de dor, de mágoa pura,

Mares desnudos y vestidos montes,

Teatro infausto de los dos amantes,

Bellísima Leonor, Manuel de Sosa

Que hoy llora su tragedia lastimosa

El mar, arrepentido

De haberlos a su playa conducido,

Cuando, abrazada con dos niños bellos,

Bebió sus almas, y ellos

La suya al mismo tiempo, cuyas vida

De lágrimas, de fe, de amor nacidas...

Abraçados, as almas soltarão... ${ }^{11}$

Algunas palabras y expresiones camonianas parecen haberse grabado nítidamente en la memoria de Lope de Vega. Aun así, la versión de la historia contada por el poeta español es diferente. Efectivamente, la unión de los amantes en la muerte es reemplazada en el texto español por la unión mortal de Leonor con los hijos. La citación, en el mismo fragmento, de un hemistiquio de la Proposición del Sepúlveda, no deja lugar a dudas sobre de dónde viene el cambio: «Belíssima Lianor/Bellísima Leonor». Lope de Vega empieza haciendo alusión al poema de Corte-Real exactamente de la misma manera que había hecho alusión a $O s$ Lusiadas, esto es, tomando de él una clausula del exordio. ${ }^{12}$ Puede ser, así mismo, que el último sintagma del párrafo constituya otra referencia al primero del Sepúlveda: "que no se debe más a un mal suceso» aludirá eventualmente al mismísimo inicio del poema: «um sucesso infelice».

Pero el compromiso del Laurel de Apolo con el Sepúlveda e Lianor se nos antoja aún mayor. Adivinamos por detrás de la concepción original de algunos versos de Lope la fuerte impresión de un fragmento muy específico de CorteReal. Comparemos los versos siguientes:

Não fica só Lianor na casa infausta,

Que de um tenro filhinho se acompanha, Que a luz vital gozou quatro perfeitos Anos, ficando o quinto interrompido.
Teatro infausto de los dos amantes, Bellísima Leonor, Manuel de Sosa, Que hoy llora su tragedia lastimosa El mar, arrepentido
11. Os Lusiadas, V, 47-48.

12. Corte-Real utiliza el hemistiquio «Belíssima Lianor", con Lianor como disílabo, no solo en la proposición (v. 5), sino también en otros varios puntos del texto. Lope de Vega parece haberse dado cuenta del carácter representativo de la expresión, como tal vez haya pasado también con "força humana» para Os Lusíadas. 
Ali co'a morta mãe o filho morto,

Ambos com morto amor em terra jazem.

Ela lhe nega o branco, amado peito,

E ele o doce, materno, amado gosto.

Ambos na solitária praia ficam

Junto das grossas ondas sepultados ${ }^{13}$
De haberlos a su playa conducido, Cuando, abrazada con dos niños bellos, Bebió sus almas, y ellos La suya al mismo tiempo

Es verdad que el texto portugués habla de Lianor con un hijo, mientras que el de Lope refiere dos. Aun así, además de la similitud entre "casa infausta» y "teatro infausto", y del término común "praia/playa», ausentes ambos en el respectivo pasaje de Os Lusiadas, el fragmento de Corte-Real parece haber inspirado a Lope de Vega la idea de reciprocidad negativa entre madre e hijos, transformando el naturalismo característico del poeta portugués en una formulación conceptista. La relación entre los dos fragmentos es reveladora. Es difícil imaginar el concepto del texto español, en el que la muerte se traduce mediante imágenes líquidas, ${ }^{14}$ sin el trasfondo del poema de Corte-Real, donde sobresale la amamantación como signo de afecto entre madre e hijo, quebrado por una desolación brutal. Y así, a través de exordios y sintagmas específicos, el Sepúlveda y Os Lusíadas emergen entretejidos en la memoria alusiva de Lope de Vega.

Siguiendo con el Laurel de Apolo, unos versos más abajo, vuelve a surgir Corte-Real, pero esta vez mencionado por su nombre. De nuevo, enlazando con referencias a Camóes:

Llegando pues la Fama

A la mayor ciudad que España aclama

Por justas causas despertar no quiso

(Y fue discreto aviso)

$70 \mathrm{Al}$ gran Sa de Miranda,

Que le dexe Melpomene le manda.

$\mathrm{Y}$ al divino Camoes:

En indianos aloes

Que riega el Ganges y produze Hidaspes,

75 Durmiendo en bronce, porfidos y jaspes

(Fortuna estraña que al ingenio aplico

La vida pobre, y el sepulcro rico)

Porque si despertaran,

Y a las Cortes Parnásides llevaran,

80 Docto Corte Real, tu nombre solo,

Aun no quedara con el suyo Apolo,

Como lo muestran oy vuestras Lusiadas

Prostrando Eneidas, y venciendo Ilíadas.

13. Ed. 1594, Canto XVII, fol. $201 \mathrm{v}$.

14. El llanto del mar, la imagen de «beber as almas» y la aliteración de las consonantes dichas «líquidas» $l l$ y $r$. 
Que triste suerte, que notables penas,

85 Acabada la vida, hallar Mecenas!

Mas no por eso puede

Dexar de ser gloriosa vuestra fama.

Los versos 81,84 y 85 hacen referencia a los problemas de mecenazgo de Corte-Real. Fue lo que pensó João Franco Barreto, ${ }^{15}$ y así lo creemos nosotros también. En el contexto de los versos de Lope de Vega, el Sepúlveda e Lianor es seguramente el poema que "halló Mecenas» solo después de la muerte de su autor (v. 85). Sin embargo, con casi total seguridad, las suertes de uno y otro poetas están siendo descritas en simultáneo. ${ }^{16}$ Así, en el díptico sobre las «Lusiadas» (vv. 82-83) y en el verso sobre la fama (87), el pronombre posesivo traduce un doble referente, Camóes y Corte-Real, asociados una vez más. Los dos son llevados a las "Cortes Parnásides», esto es, al monte Parnaso donde reinan los mayores poetas, $\mathrm{y}$ ambos merecen, a pesar de la falta de apoyos, «fama gloriosa» por sus obras, que "prostran» a Virgilio y "vencen» a Homero. Las alusiones concretas de Lope de Vega al Sepúlveda en el fragmento anterior de la misma silva, para el que ya hemos llamado la atención, nos llevan a creer que es sobre todo este el poema de Corte-Real el que él homenajea y trata de enlazar con Os Lusíadas.

Después de la Arcadia y del Laurel de Apolo, Corte-Real vuelve a brotar entre las lecturas de Lope de Vega en La Dorotea, obra impresa en 1632. En una pequeña lista de damas celebradas en poesía, no falta la protagonista del Sepúlveda, precisamente cerrando la enumeración:

DOROTEA: ¿Qué mayor riqueza para una mujer que verse eternizada? Porque la hermosura se acaba, y nadie que la mire sin ella cree que la tuvo; y los versos de su alabanza son eternos testigos que viven con su nombre. La Diana de Montemayor fué una dama natural de Valencia de Don Juan, junto a León; y Ezla, su río, y ella serán eternos por su pluma. Así la Fílida de Montalvo, la Galatea de Cervantes, la Camila de Garcilaso, la Violante de Camoens, la Silvia de Bernaldes, la Filis de Figueroa, la Leonor de Corte Real. ${ }^{17}$

15. En su Biblioteca Lusitana, manuscrito del siglo XVII cuya fotocopia se encuentra en los «Usuais» de la sala de Reservados de la Biblioteca Nacional de Portugal.

16. No se conoce ningún poema épico de Camóes además de Os Lusíadas y estos se imprimieron en vida del autor. Es verdad que las Rimas del mismo poeta esperaron unos quince ańos después de su muerte para ver la luz, pero todo indica que Lope de Vega no estaba pensando en la lírica en este caso. Por otro lado, el poeta castellano ya conoce la tradición li- teraria que atribuía a los coetáneos ingratitud hacia Camóes, como se ve por el soneto que imprimió en las Rimas del Licenciado Tomé de Burguillos que comienza diciendo: «En esto de pedir, los ricos, Fabio». El verso 77 de este fragmento del Laurel de Apolo apela inequívocamente a esta tradición.

17. Acto II, escena 2. Nótese que, de los ocho poetas mencionados, exactamente la mitad eran españoles y la otra mitad portugueses: Montemayor, Camóes, Bernardes y CorteReal. 
A buen seguro se debió en parte a la conciencia de la importancia que Lope de Vega atribuía a la poesía de Corte-Real que las Essequie Poetiche de 1636, reunidas póstumamente en su honor con toda probabilidad por don Juan Antonio de Vera y Figueroa, conde de la Roca, incluyen al poeta portugués en el desfile que acompaña a la coronación simbólica del Fénix de los ingenios. ${ }^{18}$ Presentes en el templo donde se conmemora alegóricamente el triunfo de Lope de Vega, aparecen gentes de Grecia, Roma, Italia y España. Entre los hombres de esta última región, encontramos a un puñado de ellos especialmente cercanos a Apolo, patrón de la alta poesía, o sea, eran poetas especialmente grandes e ilustres. Aquí tenemos la transcripción del fragmento relevante:

Uscì il Diafano Legislatore del giorno, Apollo Sacro, dall'Oriente del suo Palazzo, e s'incamminò al Tempio, precedendoli avanti magnifico stuolo di uomini Greci, Latini e Toscani, e più vicini alla sua persona alcuni Spagnuoli (per esser giorno dedicato all'onore del loro Poeta), fra i quali erano li più immediati al Delio Principe, Gio. de Mena, Garzilaso, Camoes, li due Luperzij, Don Diego de Mendoza, il Conte de Salinas, Herrera, Boscán, Figueroa, Ausias March, Arguixo, Medrano, Corterreal, Lobo, e Gongora.

El catálogo es bastante caótico; suficiente, a pesar de todo, para determinar un gusto ya relativamente fijado. No encontramos ningún autor que aún viviera en 1636. Corte-Real es uno de los raros espíritus que esta alegoría estimó imprescindible para la elaboración del homenaje, considerándolo implícitamente un clásico y uno de los poetas que más inspiraron al homenajeado.

En suma, el poeta portugués acompañó la carrera literaria de Lope de Vega desde el principio, y no fue olvidado ni siquiera en las exequias honoríficas compuestas en su honor. Especialmente en la Arcadia y en el Laurel de Apolo refuerza el modo de canonización promovido por primera vez por Pedro de Mariz en la segunda edición de los Diálogos de Vária História; o dicho de otro modo, Camões y Corte-Real son, al mismo nivel, los mayores poetas heroicos de Portugal, y aquellos que desafían la preponderancia de los antiguos.

\section{Cervantes, del Viaje del Parnaso al Persiles ${ }^{19}$}

Rodríguez Marín ha llamado la atención sobre dos o tres coincidencias entre la epopeya de Os Lusíadas y el Viaje del Parnaso, el poema-parodia de Miguel de Cervantes impreso en $1614 .{ }^{20}$ Uno de los episodios mencionados por el filólogo es el que hace alusión al capítulo V (versos 109 y siguientes), donde aparece

18. Sobre las Essequie y la investigación en torno al problema laberíntico de su autoría, vide Bergman (1966). Debo esta referencia y la detección del nombre de Corte-Real en el texto italiano a la gentileza y sabiduría de Mercedes Blanco.

19. Retomo aquí material que publiqué en un capítulo del volumen Vilà (2011).

20. Cf. Cervantes (1935). 
Venus intercediendo junto a Neptuno en favor de los malos poetas. Rodríguez Marín sugiere aquí la presencia de una relación en lo burlesco con el coloquio entre Venus y Júpiter en la epopeya de Camóes. De forma jocosa, Cervantes habría querido enfocar la utilización seductora de los ropajes de Venus en $O s$ Lusiadas, y de aquello que entre ellos se esconde:

Los dioses que se ven, se respetaron,

Y haciendo sus zalemas a lo moro,

De verse juntos en extremo holgaron.

Guardáronse real grave decoro,

Y procuró Ciprinia en aquel punto

Mostrar de su belleza el gran tesoro.

Ensanchó el verdugado, y dióle el punto

Con ciertos puntapiés, que fueron coces

Para el dios que las vio y quedó difunto. ${ }^{21}$

Para ser francos, la coincidencia verbal entre Cervantes y Os Lusíadas (Canto II, 37) me parece que es nula, pero la alusión ofrece suficiente vivacidad como para ser admisible, dentro del cuadro caricaturesco que el autor aplica a la mitología clásica. Conviene retener que en el mismo episodio Camóes ya había bromeado con las divinidades greco-romanas, lo que nos permite concluir que a Cervantes le gustaba parodiar fragmentos, aunque fueran épicos, con su aquel de cómico y burlesco.

Pero la epopeya de Camóes no es el único poema portugués que experimenta con el deleite jocoso potenciado por los dioses. Propongo, en efecto, que Cervantes fue esto lo que entendió precisamente cuando enlazó la reacción de Neptuno frente a las muestras de la diosa amorosa (quedó difunto) con la aparición de otro personaje susceptible a los encantos femeninos. ¿De qué personaje se trata?

Un poeta llamado Don Quincoces

Andaba semivivo en las saladas

Ondas, dando gemidos y no voces.

Con todo, dijo en mal articuladas

Palabras: «Oh señora, la de Pafo

Y de las otras dos islas nombradas,

Muévate a compasión el verme gafo

De pies y manos, y que ya me ahogo

En otras linfas que las de garrafo.

Aquí será mi pira, aquí mi rogo,

Aquí será Quincoces sepultado...2

Ahora bien, este breve episodio nos recuerda inmediatamente a la reacción física y psicológica de Proteu ante la aparición y presencia de Lianor en el Canto VI del Sepúlveda: 
Alça os olhos o velho, firma-os fixos Nos olhos de Lianor, e não podendo Sofrer a viva luz e ardente raio Que o frio coraçáo penetrou dentro, Desatinado salta, e nas inchadas, Claras ondas se esconde, mas tremendo Aparece outra vez, sem força e fraco, Com sinais de mortal, duro accidente. Já sumido nas ondas, já sobre elas, O triste em tombos anda, quasi morto. Cego, tonto, já corre, já se pára, Já sem sentido cai, já se levanta. ${ }^{23}$

Don Quincoces se comporta como Proteu en el episodio del poema portugués, con versos que detentan contacto semántico y lexical. "Andaba semivivo" en Cervantes, «anda quasi morto» en Corte-Real; «en las saladas/ondas», dice el Viaje, «nas inchadas/claras ondas», dice el Sepúlveda.

Pero hay más. Como la figura cervantina en el fragmento mencionado, Proteu profiere discursos en el Canto Sexto "com profundo gemido", como quien "geme» o "gemendo». Los términos de las intervenciones de cada personaje también se asemejan. En un momento dado, Proteu empieza: «Ó bela... movate...» (fol. 66r), mientras que el desdichado poeta del Viaje, recordémoslo, dice: "Oh señora... muévate». La aserción de que don Quincoces está «gafo/de pies y manos», es decir, paralítico, tiene su equivalente directo en la enfermedad que asalta a Proteu por exceso de emoción, estado que Corte-Real llega a comparar, en un elaborado símil de aquel Canto, precisamente con una catalepsia o rigidez muscular (fol. 62r). Incluso las repeticiones anafóricas con las que el personaje de Cervantes termina su discurso paródicamente auto-flagelador («aquí... aquí... aquí») parecen haber ido a buscar la inspiración rítmica al manierismo prominente de la auto-victimismo de Proteu:

A mim persiga Amor, a mim maltrate,

Soberbo a mim se mostre, esquivo e duro.

[...]

Ó doce vida minha, olha que morro,

No meio de mil males arrastado,

Olha esta língua muda, olha o trabalho

Do meu cansado e triste pensamento.

[...]

Vem, alma minha, vem, vem descuidada,

Descobre-me esse rosto táo fermoso.

[...]

23. Ed. 1594, Canto VI, fol. 60v. 
Vira esses olhos já, vira esses olhos

Ao penetrante ardor do peito enfermo.

[...]

Onde te vás, cruel? Onde me levas

Por força assi roubada esta alma minha? ${ }^{24}$

En el Viaje del Parnaso, el efecto «mortífero» de Venus sobre Neptuno parece como si se trasladase a la inmovilidad impotente de don Quincoces, modelado en el ya de por sí grotesco y pseudo-moribundo Proteu del poema marino de Corte-Real. No parece haber lugar a dudas que, tal vez en yuxtaposición con un intertexto camoniano, Cervantes alude consistentemente a un episodio de la obra épica de Corte-Real.

La sensibilidad cervantina por los motivos temáticos y las características de versificación presentes en el Sepúlveda están de regreso en la última obra del máximo prosador de la lengua española, Los Trabajos de Persiles y Sigismunda, ficción publicada póstumamente en 1617. En torno al capítulo $10^{\circ}$ del Libro I de esta epopeya romanesca en prosa,

...se travou a lenda de uma estreita amizade e do aproveitamento da sua figura para a personagem que na novela cervantina aparece com o nome de Manuel de Sousa Coutinho. É muito pouco provável que a fonte da história narrada nesse texto romanesco fosse uma biografia contada pelo português ao castelhano durante os arrastados días de um penoso cativeiro. Será mais prudente e próximo da verdade admitirmos, com Camilo Castelo Branco, que Cervantes apenas o conheceria de nome e que o nome lhe aproveitou, como simples recurso estético, numa aventura de amor novelesco... ${ }^{25}$

Esta conclusión autorizada y prudente no impide, sin embargo, que Cervantes haya procedido con su habitual desenfado, más o menos fingido, dando a su personaje y a sus producciones otros nombres diferentes de aquellos que podemos conocer por la genealogía y la documentación pero, en cierto modo, íntimamente ligados a estos. Algo parecido habrá pasado con «Manuel de Sosa Coitińo». Especialmente por tratarse de un Manuel de Sosa identificado como portugués y enamorado de una "Leonora» con la que pretende casarse. Así, es fácil ver que Manuel de Sosa Coitińo guarda mucha similitud con el Manuel de Sousa Sepúlveda de la epopeya en verso de Corte-Real.

Pero la certeza sobre la relación intertextual se establece allí donde la memoria alusiva de Cervantes describe la belleza y las vestimentas de Leonora, lista para su matrimonio en Portugal, con trazos indesmentibles de Lianor, cuando se prepara ella también para su boda en Goa: 


\begin{tabular}{|c|c|}
\hline Cervantes, Persiles y Sigismunda & Corte-Real, Sepúlveda e Lianor \\
\hline $\begin{array}{l}\text { Libro Primero, capítulo 10: De lo que } \\
\text { contó el enamorado portugués (edición } \\
\text { de Avalle-Arce) } \\
\text { Llegué al monasterio, que real y } \\
\text { pomposamente estaba adornado. } \\
\text { Salieron a recebirme casi toda la } \\
\text { gente principal del reino, que allí } \\
\text { aguardándome estaba, con infinitas } \\
\text { señoras de la ciudad, de las más } \\
\text { principales. Hundíase el templo } \\
\text { de música, así de voces como de } \\
\text { instrumentos, y en esto salió por la } \\
\text { puerta del claustro la sin par Leonora, } \\
\text { acompañada de la priora y de otras } \\
\text { muchas monjas, vestida de raso } \\
\text { blanco acuchillado con saya entera a } \\
\text { lo castellano, tomadas las cuchilladas } \\
\text { con ricas y gruesas perlas. Venía forrada } \\
\text { la saya en tela de oro verde; traía los } \\
\text { cabellos sueltos por las espaldas, tan } \\
\text { rubios que deslumbraban los del sol, y } \\
\text { tan luengos, que casi besaban la tierra; } \\
\text { la cintura, collar y anillos que traía, } \\
\text { opiniones hubo que valían un reino } \\
\text { [...] Estaba hecho un modo de teatro } \\
\text { en mitad del cuerpo de la iglesia, donde } \\
\text { desenfadadamente y sin que nadie los } \\
\text { empachase se había de celebrar nuestro } \\
\text { desposorio. Subió en él primero la } \\
\text { hermosa doncella, donde al descubierto } \\
\text { mostró su gallardía y gentileza. Pareció } \\
\text { a todos los ojos que la miraban lo que } \\
\text { suele parecer la bella aurora al despuntar } \\
\text { del día, o lo que dicen las antiguas } \\
\text { fábulas que parecía la casta Diana en } \\
\text { los bosques, y algunos creo que hubo } \\
\text { tan discretos que no la acertaron a } \\
\text { comparar sino a sí misma. }\end{array}$ & $\begin{array}{l}\text { Canto IV: Neste quarto canto se celebra o } \\
\text { casamento... } \\
\text { Do paterno aposento sai a dama } \\
\text { Por espanto julgada ali entre todos, } \\
\text { Os ares alegrando com tal graça } \\
\text { Que a bela Citareia se lhe humilha. } \\
\text { Dos seus louros cabelos leva feitas } \\
\text { Em torno da cabeça ũas laçadas } \\
\text { Guarnecidas de perlas de alto preço } \\
\text { Com estranho lavor de obra admirável. } \\
\text { Leva ricos firmais que os olhos cegam } \\
\text { Com vivo resplandor de puros raios, } \\
\text { Mas se ela os olhos alça, outros despede } \\
\text { Que sem remédio ardendo deixam } \\
\text { almas. } \\
\text { Leva roupa comprida ao francês uso, } \\
\text { De ũa seda que à cor do prado excede, } \\
\text { Justa no corpo até à cintura, e dela, } \\
\text { Afastando-se, em roda a terra toca. } \\
\text { Largas mangas em mil golpes cortadas, } \\
\text { Tomadas com botóes de grossas perlas, } \\
\text { E o branco, liso colo rodeado } \\
\text { Da beleza que só Bisnagá cria. } \\
\text { Ũa ditosa cinta estreitamente } \\
\text { O belíssimo corpo abraça, e creio } \\
\text { Que disto o Sousa tanto cioso iria } \\
\text { Quanto a todos os mais faria enveja. } \\
\text { Cai-lhe do ombro esquerdo um rico } \\
\text { manto } \\
\text { Na mesma seda e cor conforme à veste. } \\
\text { [...] } \\
\text { Não cabem pelas ruas os que vinham } \\
\text { Por ver as graças mil de seu sembrante. } \\
\text { Qual a fermosa aurora se nos mostra } \\
\text { Em primavera rosas derramando } \\
\text { Ao derrador do céu, ou qual Diana } \\
\text { Quando do amado irmáo toma luz pura, } \\
\text { Tal se mostra Lianor... }\end{array}$ \\
\hline
\end{tabular}

Los textos comparten ciertos presupuestos culturales, sobre la effictio de la mujer joven y bella, sobre los vestidos de boda, sobre ideales de presencia carismática. Pero, más allá de todo esto, existe una intertextualidad concreta. Ambos representan vestidos de raso («seda», en portugués), tienen preferencia por el verde ("cor do prado» y "cor conforme à veste», en portugués; «tela de oro verde», en español), mencionan joyas, collares, cinturones y drapeados, y mien- 
tras el poeta luso habla de "roupa comprida ao francés uso», el Persiles prefiere, para aquel matrimonio portugués, «saya entera a lo castellano»... Destacamos, sobre todo, dos momentos de inconfundible palimpsesto, que hemos señalado en cursiva: primero, aquel en el que los cortes de los vestidos están, tanto en el caso portugués como en el español, prendidos con perlas; después, en una apropiación deliberada, Cervantes se sirve de un doble símil con la misma alternativa entre la Aurora y Diana que encontramos en el fragmento de Corte-Real. ${ }^{26}$

Se impone, por lo tanto, una reinterpretación de la obra de Cervantes, y particularmente de este episodio del «enamorado portugués», a la luz de una referencialidad completamente nueva. ${ }^{27}$ Las fiestas de los desposorios en el Sepúlveda, por no decir todo el poema de Corte-Real en su conjunto significativo de la historia trágico-amorosa que relata, fue estímulo para la imaginación literaria cervantina en el Persiles, como la grotesca figura de Proteu lo había sido para el Viaje del Parnaso. En los últimos años de su carrera literaria el gran prosista se dejó empapar de la forma más variada, desde temas a estilemas, por el gran poema narrativo portugués.

\section{Calderón, $A$ secreto agravio, secreta venganza}

La íntima ligazón entre la recepción de Corte-Real y la de Camóes que hemos encontrado en la Arcadia y en el Laurel de Apolo de Lope de Vega, así como en el Viaje del Parnaso de Cervantes, sucede también en la obra de Pedro Calderón de la Barca, otra figura de primera línea de la literatura del Siglo de Oro. Efectivamente, uno de sus dramas de honor de la década de $1630^{28}$, A secreto agravio, secreta venganza, no solo está construido sobre una base lusitana, sino que también se asocia inmediatamente a las dos mayores épicas narrativas del país vecino. De ellas, es el Sepúlveda la que posee una función más palpable en la obra de Calderón. En una acción en la que el escenario y el carácter portugués de la mayoría de los personajes se alían en un enredo de amores, celos, matrimonio y homicidio, hay una escena, casi al arranque de la pieza en que el vínculo al poema de Corte-Real asume un relieve especial.

26. El doble símil de Corte-Real se inspiró probablemente en el pasaje en prosa de Sannazaro donde se describe a la bella Amaranta: «divenne non altrimente vermiglia nel viso che suole talvolta il rubicondo aspetto de la incantata luna, o vero ne lo uscire del sole la purpurea aurora mostrarsi a' riguardanti» $(A r-$ cadia, IV, 9). La ausencia de otros puntos de contacto con la descripción italiana, sin embargo, no nos permite dudar que Cervantes, en su composición de la figura de Leonora, tuvo principalmente en su pensamiento el poema portugués.
27. El desconocimiento del Sepúlveda y la importancia de la que se revistió la lectura del poema portugués en el universo literario del $\mathrm{Si}$ glo de Oro seguirá, si no se corrige, induciendo a errores de interpretación, como sucede en una obra de calidad como el libro de Grilli (2004: 209-17), sobre el tópico del «viajante portugués» y este episodio del Persiles.

28. Existe un manuscrito de la pieza, datado en 1635, en la Biblioteca Nacional de España. La primera edición es la de la Segunda parte de las comedias de don Pedro Calderón de la Barca, de 1637. 
Estamos en la Jornada Primera del drama. Don Juan da Silva, recién llegado a Lisboa desde Oriente, cuenta a Don Lope de Almeida, aquel que será el protagonista de la tragedia familiar en torno a la cual se desenvuelve el drama de Calderón, la historia que vivió en Goa. Esta vivencia en la India refleja avant la lettre mucho de aquello que sucederá durante el resto de la intriga.

Como pórtico de la intervención de Don Juan, se proyecta el recuerdo de Os Lusiadas: ${ }^{29}$

La nobleza lusitana

de su fortuna fió

100 naves, que ciertas exceden

las fingidas de Jasón.

Dejo esta alabanza a quien pueda con más dulce voz contar los famosos hechos

105 de esta invencible nación, porque el gran Luis de Camóes, escribiendo lo que obró, con pluma y espada muestra ya el ingenio, ya el valor

110 en esta parte.

Descendemos unos versos y nos encontramos la singular historia que tanto relieve tiene para conocer el impacto que el poema de Corte-Real, en particular su Canto Primero, causó en el espíritu del dramaturgo español:

Había en Goa una señora, hija de un hombre a quien dio grande cantidad de hacienda

125 codicia y contratación.

Era hermosa, era discreta, que, aunque enemigas las dos, en ella hicieron las paces hermosura y discreción.

130 Servila tan venturoso que merecí algún favor; pero ¿quién ganó al principio que a la postre no perdió? ¿quién fue antes tan felice

135 que después no declinó?, porque son muy parecidos juego, fortuna y amor.

Don Manuel de Sosa, un hombre

- hijo del gobernador

29. Transcribo de Calderón de la Barca (2011). 
140 Manuel de Sosa - por sí de mucha resolución, muy valiente, muy cortés, bizarro y cuerdo - que yo, aunque le quité la vida,

145 no he de quitarle el honor -,

- que este es el nombre que dio ocasión a mi ventura y a mi desdicha ocasión -,

150 en Goa públicamente era mi competidor. Poco cuidado me daba su amorosa pretensión, porque siendo, como era,

155 el favorecido yo,

la pena del despreciado

hizo mi dicha mayor.

Los parecidos de este enredo con los dos Cantos iniciales del Sepúlveda saltan a la vista. La historia, inserta en una modulación dramática y teatral, se nos ofrece desde la perspectiva de uno de los protagonistas, y no desde la de un narrador exterior a la acción. Salvo esta excepción, en la casi totalidad se presienten alusiones a los versos de Corte-Real. Son dos los pretendientes de la misma dama, uno de los cuales con idénticos nombre y apellido que el héroe de la epopeya portuguesa. Calderón trastoca los papeles: el gobernador del Estado de India es el padre de uno de los pretendientes, y no el de la amada; el candidato con éxito aparente, quien despierta los deseos de la dama, es el otro (don Juan da Silva; en el Sepúlveda, Luís Falcáo), y no Manuel de Sousa. Esto no obsta para que la sintonía con el testo de Corte-Real sea patente y constante.

La dama, cuyo nombre resulta extraño a la tradición hispano-lusa (la protagonista de $A$ secreto agravio, secreta venganza también se llama Leonor...), ${ }^{30}$ es hija de un hombre que enriqueció por medios de dudosa moral (vv. 123-25), exactamente como Garcia de Sá en el poema portugués:

Trata-se o grande dote, desejado

Do pai, que busca só bens da fortuna,

Só riquezas pretende. ${ }^{31}$

La declaración de que el padre de Lianor se movía por codicia parece trasplantada a las redondillas de Calderón y al padre de Violante.

30. ¿Tendrá algo que ver Violante con Camóes? Recordemos el nombre de la amada camoniana que Lope de Vega retuvo en La Dorotea, citada arriba. De ser así se acentuaría el entrelazado de los dos épicos portugueses en la memoria intertextual hispánica.

31. Canto I, vv. 584-6. 
Las interrogaciones retóricas que clasifican, al tiempo, juego, fortuna y amor (vv. 132-7), se asemejan inusitadamente a la serie de interrogaciones con la que Corte-Real abre el Canto Sexto, pensando en la desdichada pareja:

Quem se viu enlevado em suas dilícias

Que não sentisse o fim, amargo e triste?

[...]

Quem fundamento fez de seus prazeres

Que em lágrimas e dor não acabasse?32
Pero ¿quién ganó al principio

Que a la postre no perdió?

¿Quién fue antes felice

Que después no declinó?

El carácter del amante Don Juan, una vez más en un cambio de situaciones, recoge términos utilizados para describir el estado de ánimo de Manuel de Sousa en el poema portugués, en particular en los dos últimos versos:

E vendo-se ele ser o mais perdido

Julga-se com rezão por mais ditoso. ${ }^{33}$ la pena del despreciado

hizo mi dicha mayor.

Aunque el referente sea otro, la antítesis — o sea, la forma textual asumida por la idea- es casi idéntica. El Sepúlveda e Lianor parece impregnar el drama de Calderón también al nivel de la letra.

Por no faltar, no falta ni siquiera la Escena del Paseo, como en el Canto Primero de Corte-Real. Si en el Sepúlveda el paseo da inicio a la reciprocidad amorosa que, solo más tarde, desembocará en el asesinato de uno de los pretendientes, en Calderón el paseo se convierte en el escenario del crimen al que ya hemos hecho alusión en el texto supra-citado («le quité la vida», 144). También la comparación de la dama con el Sol une a los dos paseos, calderoniano en el naciente, portugués en el poniente, ambos en Goa:

E assi como se vê (quando é trasposto

O claro Sol) o ar ficar sombrio,

Envolto em manto negro da confusa,

Húmida, tenebrosa, muda noite,

Assi no coração do triste amante

Um cerrado bulcão fica estendido

Que todo ali o cobre e assombra, quando

O seu fermoso Sol perdeu de vista. ${ }^{34}$
Un día que el sol hermoso salía _ipluguiera a Dios sepultara eterna noche su continuo resplandor!salió con el sol Violante: bastaba pedirle yo que aun el uno no saliera, para que salieran dos. ${ }^{35}$

El cortejo que les sigue los pasos, observando, no es diferente:

Sabido este caminho, vão trás ela

Seguindo-a muitos olhos, muitas almas,

E muitos coraçóes todos rendidos. ${ }^{36}$
Violante. Iba tan airosa que allí ninguno dejó de poner el alma en ella. ${ }^{37}$
32. Ed. 1594, Canto VI, fol. 36v.

33. Canto I, vv. 314-15.

34. Canto I, vv. 548-555.
35. A secreto agravio..., vv. 178-180.

36. Canto I, vv. 341-3.

37. A secreto agravio..., vv. 178-180. 
Un estudio de la concepción general del drama de Calderón a la luz del poema de Corte-Real podría evidenciar aun más puntos comunes. El texto lusitano habría propiciado, tal vez, en Calderón el ejemplo más poderoso del estereotipo portugués concebido por los españoles de entonces: con dotes de amante y celosos. ${ }^{38}$ La propia cuestión del honor, tan decisiva en $A$ secreto agravio, secreta venganza y tan unida a la referencialidad sistemática del supuesto carácter de los portugueses, encuentra un representante evidente en la configuración inicial del enredo humano en el Sepúlveda. Garcia de Sá, tal como lo retrata el poeta, exhibe con abundancia los peligrosos excesos de la honradez:
...brama e arde em fúria
O colérico pai, que prometido
E dado tem palavra ao Falcáo, e antes
A vida perderá que não cumpri-la.
[...]
«A palavra que tenho ao Falcáo dada,
Por mim será cumprida, e não presuma
Levar Manuel de Sousa o que me manda
Dizer avante mais, pois é escusado,
Que primeiro estas mãos serão verdugo
Da filha que naceu pera matar-me,
Primeiro a enterrarei viva, que passe
Esta falta por mim, tendo ela a culpa.» ${ }^{39}$

Por supuesto que Calderón no necesitaba la violencia de estas palabras, en las que los imperativos del honor tienen más importancia que los de la vida, para elaborar una reflexión dramática alrededor del tema, pero es muy posible -especialmente en el marco de la intertextualidad que hemos estado observando aquí- que esas mismas palabras hayan aportado alguna contribución a la concepción de la pieza.

En la intriga del drama calderoniano, tiene especial importancia la ocultación del crimen. Don Lope de Almeida, el protagonista, mata a su esposa y al amante de ésta, pero nunca llegará a ser pública su culpa en los asesinatos. En el Sepúlveda, Manuel de Sousa mata al rival, pero ningún otro personaje da muestras de conocer el secreto. Una de las cosas que Don Lope aprende de la narrativa de las desdichas de Goa de Don Juan da Silva es que un crimen de honor no compensa si se comete a cara descubierta. Haciendo un paralelismo, casi podríamos añadir que una de las cosas que Calderón aprendió del poema de Corte-Real fue a reflexionar sobre la cuestión del homicidio supuestamente honroso. La ligazón que el poeta portugués establece entre el crimen y el casti-

38. Erik Cohen, en la introducción a la edición que estamos siguiendo (Calderón de la Barca, 2011), hace observaciones importantes sobre el aspecto «portugués» del drama calderoniano.

39. Canto I, vv. 616-19 y 628-35. 
go de Sepúlveda no existe en otras versiones del naufragio - recordemos que Camóes, sin ir más lejos, lo transforma en uno de los ejemplos de castigo por el atrevimiento portugués a cruzar los océanos. La concepción de Corte Real, para todos los efectos, habrá surgido como poética a los ojos de Calderón, y colmada de elementos interesantes para su realización dramática, mediante estratagemas donde amor, celos y honor alternan con muertes por infortunio y asesinatos solapados.

\section{Solórzano Pereira y Tirso de Molina}

Entre otros varios autores que son testigo de la fama de Corte-Real en el mundo hispánico, nos interesa destacar a dos de ellos por el interés que tienen para la comprensión de la recepción del Sepúlveda e Lianor.

Uno de ellos es Juan de Solórzano y Pereira, célebre historiador y muy reputado intelectual que dedica su monumento histórico-jurídico, Disputationes De Indiarum Jure, a las llamadas Indias Occidentales. En el Libro Primero de esta obra hace uso de un rol sustancial de fuentes portuguesas referentes al imperio oriental lusitano entre las que se encuentran los Diálogos de Vária História de Pedro de Mariz (a quien Solórzano llama «Damariz»). Ya sea por el influjo de esta fuente o por su acceso a otras, el autor nombra a Corte-Real como uno de los grandes cantores de materias orientales, emparejándole con Camóes:

Plurima etiam elegantissimis carminibus Lusitano sermone cecinerunt Ludov. Camoës, \& Hiero. de CorteReal, quos non iniuria Virgilio, \& Horatio pares esse, quis dixerit. $^{40}$

El más reciente equipo de traductores españoles de la obra de Solórzano vertió este fragmento de la forma siguiente:

Muchas hazańas cantaron también en bellíssimos versos Luis Camoens y Jerónimo de Corte Real, que sin agravio podría uno afirmar que corren parejas con Virgilio y Horacio. ${ }^{41}$

El empleo de elegantissimis para los dos poetas sugiere que el historiógrafo español consultó la primera edición de los Diálogos de Mariz donde, como ya hemos visto, el Segundo Cerco de Diu y Os Lusíadas merecen el mismo epíteto. Sin embargo, la colocación de ambos poetas en el mismo plano superior, sin jerarquización, apunta preferencialmente para la lectura de la edición de 1597-

40. Solórzano Pereyra (1629), p. 30, col. b p. 31, col. a. En la segunda edición (Solórzano Pereyra, 1672), la frase que respecta a los poetas portugueses se presenta ligeiramente diferente, pero sin afectar al contenido: "Plurima etiam elegantissimis carminibus, Lusitano sermone cecinerunt Ludovic. Camoës, \& Hieron. de Corte Real, quos non iniuria Virgilio, \& Horatio pares esse, quis dixerit» (p. 18, col. b).

41. Solórzano y Pereira (2001: 117). 
99. ${ }^{42}$ De cualquier manera, no podemos tener la seguridad de a cuál de los dos poemas en lengua portuguesa de Corte-Real se estaría refiriendo Solórzano ya que tanto en el Sepúlveda e Lianor como en el Cerco de Diu se tratan asuntos relacionados con la India. Lo más probable es que estuviera pensando en ambos. En 1629, año en que se imprimieron las Disputationes de Solórzano, estamos en vísperas del gran homenaje de Lope de Vega al Sepúlveda y de la influencia notoria de este poema en la pieza teatral de Calderón, de la década de 1630 las dos. Nos parece legítimo suponer, por lo tanto, que la apreciación de Juan Solórzano denota el peso excepcional de la epopeya póstuma de Corte-Real en el espíritu de los lectores coetáneos.

Otro autor español digno de mención que, indiscutiblemente, leyó la obra portuguesa en la misma época fue Tirso de Molina, pseudónimo con el que se dio a conocer Fray Gabriel Téllez. No es ningún secreto el interés que el creador del donjuanismo tenía por Portugal y los portugueses. La pieza Escarmientos para el cuerdo es una de las que va más lejos en el gusto por las cosas lusitanas, pues toda ella depende de fuentes portuguesas que giran en torno a la expansión oriental, cuidadosamente escogidas. Contemporáneo del drama de Calderón que ya hemos analizado, dado que se imprimió por primera vez en la Parte Quinta de sus Comedias, en 1636, Escarmientos para el cuerdo reescribe el enredo de los amores y tragedias de Lianor y Manuel de Sousa, en el que depende, sobre todo, del poema de Corte-Real.

No repetiremos aquí los resúmenes de la intriga, bien elaborados por $\mathrm{J}$. Cândido de Oliveira Martins y Gregorio Torres Nebrera. ${ }^{43}$ Nos limitaremos a adelantar qué aspectos atribuidos por los críticos a la capacidad inventiva de Tirso en aquella narrativa son efectivamente heredados de la narrativa del $\mathrm{Se}$ púlveda. Se nos ocurre pensar en buena parte de las vertientes romanescas de la pieza (la cuestión amorosa, el hijo bastardo, el ethos de Garcia de Sá etc.), en el pormenor de la intermediaria para las cartas amorosas (Acto I de Escarmientos, Cantos I y II de la epopeya portuguesa), o en la transformación del naufragio y de las muertes en castigo por los crímenes del protagonista. ${ }^{44}$

42. Es lo que sugieren los editores/traductores hodiernos de Solórzano (2001: 630).

43. Martins (1997: 80-83); el texto de Torres Nebrera está en Molina (2010: 18-20).

44. Uno de los más importantes estudiosos del teatro tirsiano, Serge Maurel, aboga por la originalidad de Escarmientos para el cuerdo en el primer y último punto que destacamos aquí, dado el conocimiento insuficiente de los contenidos del poema de Corte-Real (a pesar de haber sido recordado e incluso citado por el investigador). Según Maurel, la intriga romanesca «constitue la part de fiction de la "comedia» et la part d'invention du dramaturge», sin antecedentes. En lo tocante al desenlace, afirmaba: "Tirso a donc abondamment utilisé les historiens portugais pour le récit de ce tragique dénouement. Mais à ce drame il donne des raisons qui lui sont propres: pour l'histoire, Manuel de Sousa est victime des éléments déchaînés, d'une nature hostile et de ses sauvages habitants; pour Tirso, don Manuel est victime de ses fautes, et le malheur qui l'accable est châtiment de Dieu» (1971; 361, 174). Claro que la idea de que la tragedia resulta de la culpa del héroe y del castigo divino es verdaderamente cultivada en el poema portugués. 
Tal y como sucede en la obra contemporánea de Calderón que hemos estudiado más arriba, también Tirso se basa en la intriga solamente revelada en el Sepúlveda, en el Canto Primero en particular. Y al igual que Cervantes en el Persiles, Tirso no emparentó su texto con la memoria épica de Camóes. Estos autores fundamentales del Siglo de Oro hicieron lecturas individuales del poema de Corte-Real, identificando en él aspectos que consideraron provechosos para sus propias creaciones. Desde semejante planteamiento, nos entusiasma descubrir que la historia que solamente el Sepúlveda celebra fue reinventada una y otra vez para el palco español, ganando así una nueva vida y otra proyección. 


\section{Bibliografía}

Barreto, João Franco, Biblioteca Lusitana (MS)

Bergman, Hannah E., Recensión de In onor della Fenice Ibera. Über die "Essequie poetiche di Lope de Vega" (Venedig 1636] nebst einer kommentierten Ausgabe der "Orazione del Cavalier Marino" und des "Ragguaglio di Parnaso» por Wido Hempel, Hispanic Review, vol. 34, no 2 (1966), pp. 163-8.

Calderón de la Barca, Pedro, A secreto agravio, secreta venganza, ed. Erik Coenen, Madrid, Cátedra, 2011.

Castro, Aníbal Pinto de, «Introdução» in Frei Luís de Sousa, Vida de D. Frei Bartolameu dos Mártires, Lisboa, Imprensa Nacional - Casa da Moeda, 1984, pp. xiii-xxxix.

Cervantes, Miguel de, Viaje del Parnaso, ed. Francisco Rodríguez Marín, Madrid, C. Bermejo, 1935.

Figueiredo, Fidelino de, «Camoes e Lope», Revue de Littérature Comparée, Año $18^{\circ}$, n. ${ }^{\circ}$ 1, París, enero-marzo de 1938, pp. 160-171.

GriLli, Giuseppe, Literatura caballeresca y re-escrituras cervantinas, Alcalá de Henares: Centro de Estudios Cervantinos, 2004.

Mariz, Pedro de, Dialogos de varia historia em que sumariamente se referem muytas cousas antiguas de Hespanha..., Coimbra, na Oficina de Antonio de Mariz, 1594.

-, Dialogos de varia historia em que sumariamente se referem muytas cousas antiguas de Hespanha..., Coimbra, na Oficina de Antonio de Mariz, 1597/1598 (en el colofón: «acabouse de imprimir a segunda vez (...) 8 de Abril 1599»).

Martins, J. Cândido, Naufrágio de Sepúlveda. Texto e Intertexto, Lisboa: Replicação, 1997.

Maurel, Serge, L'Univers Dramatique de Tirso de Molina, Poitiers: Publications de la Université, 1971.

Molina, Tirso de, La prudencia en la mujer, edición de Gregorio Torres Nebrera, Madrid: Cátedra, 2010.

Sannazaro, Jacopo, Arcadia, ed. Francesco Erspamer, Milán, Mursia, 1990.

Santa Maria, (Padre) Francisco, Anno Historico, Diario Portuguez, Noticia abreviada de pessoas grandes, e cousas notaveis de Portugal, Lisboa, Domingos Gonçalves, 1744.

Solórzano y Pereyra, Juan de, D. Philip. IV. Hisp. et Ind. regi opt. max. Ioannes de Solorzano Pereira [...] Disputationem de Indiarum iure, sive de iusta indiarum Occidentalium inquisitione, acquisitione, et retentione. Tribus Libris Comprehensam. Madrid: Francisco Martínez, 1629.

—, Disputationes de Indiarum iure, sive de iusta indiarum Occidentalium inquisitione..., Lyon, 1672.

—, De Indiarum Jure (Liber I: De inquisitione Indiarum), ed. bilingüe de C. Baciero, L. Baciero, A. M. García Añoveros, J. M. Soto, col. "Corpus Hispanorum De Pace», Segunda Serie, Madrid, CSIC, 2001. 
Vega Carpio, Lope de, Arcadia, prosas y versos, Madrid, Luis Sanchez, 1598.

—, Arcadia, prosas y versos, a/c Antonio Sánchez Jiménez, Madrid, Cátedra, 2012.

—, Laurel de Apolo, Madrid, Juan González, 1630.

—, Laurel de Apolo, ed. Antonio Carreño, Madrid, Cátedra, 2007.

VILÀ, Lara (ed.), Estudios sobre la Tradición Épica Occidental (Edad Media y Renacimiento), Madrid-Bellaterra, 2011. 
